\title{
Analisis Proses Bisnis pada Dinas Perdagangan Kota XYZ dengan Menggunakan Business Process Management Lifecycle
}

\author{
Hendy Maulana Jaya Saputra ${ }^{1}$, Deya Elisda Marviainyda ${ }^{2}$, Riska Ayu Larasati ${ }^{3}$, Muhammad \\ Zabarij Almasz Addaffa, Lovinta Happy Atrinawati ${ }^{5}$ \\ 1,2,3,4,5 Sistem Informasi, Matematika dan Teknologi Informasi, Institut Teknologi Kalimantan, Balikpapan. \\ Email: 10171034@student.itk.ac.id
}

\begin{abstract}
The XYZ City Trade Office is a government organization that is engaged in regulating the stability of staple food through trade activities in XYZ City. This study aims to identify the existing business processes at the XYZ City Trade Office, in addition to being identified, this study will also conduct analysis and improvement and redesign of the business processes currently being implemented by the XYZ City Trade Office. The steps taken to identify business processes are by conducting interviews related to the duties and functions of each entity and the Office to stakeholders in the XYZ City Trade Office. The methodology used to identify, describe, analyze and redesign business processes is the Business Process Life Cycle (BPM Lifecycle). The identification results are 36 business processes, and 3 of them are export business processes, import business processes, and processes Business Can Send and Evaluate. In all three business processes, further evaluation and analysis are carried out. The analysis and evaluation is to first describe the business process in the form of business process modeling notation using bizagi modeller, then measure the quality of business processes, and analyze weaknesses, and compare with the duties and functions of the Ministry of Trade of the Republic of Indonesia, so that improvements to the process for the third the business process. Improvements for the Export and Import business processes are by adding oversight processes at the shipping stage, and business process improvements Conducting Shipment and Evaluation is by removing the activities of Giving Delivery News.
\end{abstract}

Keywords: Business Process, BPMN, BPM Lifecycle, Bizagi Modeller

\begin{abstract}
Abstrak
Dinas Perdagangan Kota XYZ adalah badan pemerintahan yang bergerak untuk mengatur stabilitas bahan pangan pokok melalui kegiatan perdagangan di Kota XYZ. Penelitian ini bertujuan untuk mengidentifikasi proses bisnis yang ada pada Dinas Perdagangan Kota XYZ, selain diidentifikasi, pada penelitian ini juga akan dilakukan analisis dan perbaikan serta redesain dari proses bisnis yang saat ini sedang diterapkan oleh Dinas Perdagangan Kota XYZ. Tahapan yang dilakukan untuk mengidentifikasi proses bisnis adalah dengan melakukan wawancara terkait tugas dan fungsi setiap entitas dan Dinas tersebut kepada pemangku kepentingan yang terdapat pada Dinas Perdagangan Kota XYZ. Metodologi yang digunakan untuk mengidentifikasi, menggambarkan, menganalisis dan mendesain ulang proses bisnis adalah dengan Siklus Hidup Manajemen Proses Bisnis (BPM Lifecycle).. Hasil identifikasi adalah berupa penemuan sebanyak 36 proses bisnis, dan 3 diantaranya adalah proses bisnsi Ekspor, proses bisnis Impor, dan proses bisnsi Melakukan Pengiriman dan Evaluasi. Pada ketiga proses bisnis tersebut dilakukan evaluasi dan analisis lebih lanjut. Analisis dan evaluasi yang dilakukan adalah menggambarkan terlebih dahulu proses bisnsi kedalam bentuk notasi pemodelan proses bisnis (BPMN) dengan menggunakan Bizagi Modeller, kemudian dilakukan pengukuran terhadap kualitas proses bisnis, dan analisis kelemahan, serta membandingkan dengan tugas dan fungsi Kementerian Perdagangan Republik Indonesia, sehingga didapatkan perbaikan proses untuk ketiga proses bisnis tersebut. Perbaikan untuk proses bisnis Ekspor dan Impor adalah dengan menambahkan proses pengawasan pada tahap pengiriman, dan perbaikan proses bisnis Melakukan Pengiriman dan Evaluasi adalah dengan menghapus aktivitas Memberikan Kabar Pengiriman.
\end{abstract}

Kata Kunci: proses bisnis, BPMN, Siklus Hidup BPM, Bizagi Modeller 


\section{Pendahuluan}

Dinas Perdagangan Kota XYZ adalah badan pemerintahan yang bertugas untuk menjaga stabilitas bahan pangan pokok di Kota XYZ melalui kegiatan perdagangan. Selain itu, tugas dari Dinas Perdagangan Kota XYZ adalah untuk menyelenggarakan urusan pemerintahan di bidang perdagangan dan tugas pembantuan sesuai ketentuan peraturan perundang-undangan. Dalam menjalankan tugasnya, Dinas Perdagangan Kota XYZ juga berada di bawah naungan Kementerian Pemberdayaan Aparatur Negara dan Reformasi Birokrasi Republik Indonesia.

Proses bisnis terdiri atas rangkaian aktifitas yang saling terkait. Proses bisnis membantu perusahaan atau instansi dalam mencapai tujuan bisnis tertentu. Proses bisnis dapat dijalankan oleh manusia atau sistem. Pemetaan proses bisnis dibutuhkan agar perusahaan dapat menggambarkan proses bisnis yang ada. Pemetaan proses ini digunakan untuk mengevaluasi dan melakukan perbaikan terhadap proses bisnis yang saat ini sedang berjalan di perusahaan.

Kementerian Permberdayaan Aparatur Negara dan Reformasi Birokrasi Republik Indonesia bekontribusi dalam memberikan arahan kepada instansi pemerintahan, salah satunya adalah yang tercantum dalam Peraturan Menteri Pendayagunaan Aparatur Negara Dan Reformasi Birokrasi Republik Indonesia Nomor 19 Tahun 2018 Tentang Penyusunan Peta Proses Bisnis Instansi Pemerintah. Peraturan Menteri (Permen) ini berisikan intruksi terkait pemetaan proses bisnis yang bertujuan untuk menjadi acuan bagi instansi pemerintah untuk menggambarkan hubungan kerja yang efektif dan efisien antar unit organisasi untuk menghasilkan kinerja sesuai dengan tujuan pendirian organisasi agar menghasilkan keluaran yang bernilai tambah bagi pemangku kepentingan. Peraturan Menteri ini meminta agar seluruh instansi pemerintahan Republik Indonesia agar melakukan pemetaan proses bisnis, tidak terkecuali Dinas Perdagangan Kota XYZ.

Dinas Perdagangan Kota XYZ belum memiliki dokumen proses bisnis, sehingga PERMENPAN RB Nomor 19 Tahun 2018 ini belum diimplementasikan di Dinas ini. Oleh karena itu perlu dilakukan langkah-langkah pemetaan proses bisnis agar Peraturan Menteri ini dapat diimplementasikan. Selain dilakukan pemetaan proses bisnis, perlu juga dilakukan analisis terhadap proses bisnis yang ada di Dinas Perdagangan Kota XYZ agar dapat berjalan secara efektif dan efisien.

\section{Metodologi}

Metode penelitian yang dilakukan pada permasalahan proses bisnis di Dinas Perdagangan Kota XYZ adalah dengan menggunakan menggunakan metodologi waterfall. Adapun bentuk bagan dari metodologi tersebut adalah seperti gambar berikut:

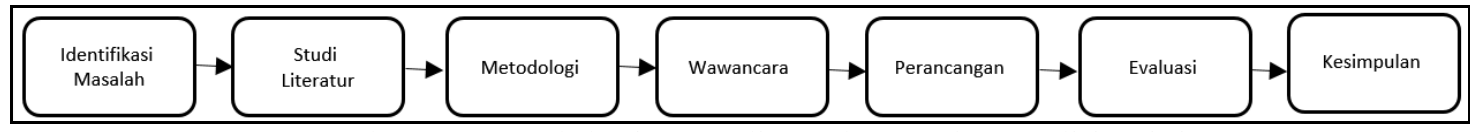

Gambar 1: Metodologi yang digunakan pada penelitian ini

Bussiness Process Management Life Cycle. Metode ini terbagi menjadi beberapa tahapan yang diantaranya adalah Process Identification, Process Discovery, Process Analyze, Process Redesign, Process Implementation, Process Monitoting and Controling. Pada Process Identification dan Process Discovery dilakukan dengan cara mewawancarai pihak-pihak terkait dari Dinas Perdagangan Kota XYZ, Process Analyze dilaksanakan dengan menganalisis proses bisnis yang telah diperoleh pada tahapan sebelumnya, dan untuk tahapan Process Redesign dilakukan dengan mendesain kembali proses bisnis yang telah didapatkan berdasarkan hasil dari Process Analyze. Pada penelitian kali ini, tahapan yang dilakukan adalah hanya sampai kepada tahap Process Redesign. Adapun penjelasan pada setiap langkah di metodologi adalah seperti berikut.

\subsection{Identifikasi Masalah}




\section{Analisis Proses Bisnis pada Dinas Perdagangan Kota XYZ dengan Menggunakan Business Process Management Lifecycle}

Pada tahapan identifikasi masalah, dilakukan pencarian institusi apa yang akan diambil sebagai kasus pembelajaran. Setelah menetapkan Dinas Perdagangan Kota XYZ sebagai kasus pembelajaran, selanjutnya dilakukan peninjauan masalah dan evaluasi terhadap proses bisnis yang ada pada Dinas Perdagangan Kota XYZ.

\subsection{Studi Literatur}

Studi literatur dilakukan untuk mencari landasan yang terhubung dengan tugas besar ini serta penelitian-penelitian terdahulu yang terkait dengan kasus pembelajaran yang diambil. Adapun penelitian yang pernah dilakukan adalah seperti berikut:

Tabel 1: Penelitian terdahulu

\begin{tabular}{|c|c|c|}
\hline Tahun & Penulis & Judul \\
\hline 2007 & Vergidis, dkk & $\begin{array}{l}\text { Business Process Analysis And Optimization: Beyond } \\
\text { Reengineering }\end{array}$ \\
\hline 2010 & Sri Agustina Rumapea & $\begin{array}{l}\text { Analisis Proses Bisnis Pada Distributor } \mathrm{XYZ} \\
\text { Menggunakan Tools Pemodelan IDEF0 }\end{array}$ \\
\hline 2015 & Moch Ali Ramdhani & 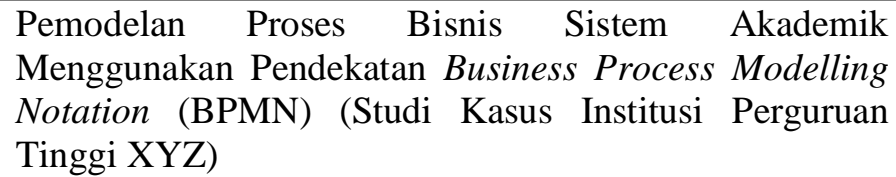 \\
\hline
\end{tabular}

\subsection{Metodologi}

Metodologi pada penelitian ini yaitu menentukan gambaran umum projek tugas besar ini, serta menentukan tahapan-tahapan yang dilakukan selama proses pengerjaan tugas besar ini. Adapun metodologi yang digunakan yaitu dengan menggunakan Business Process Management Lifecycle. Tahapan pada Business Process Management Lifecycle adalah seperti berikut:

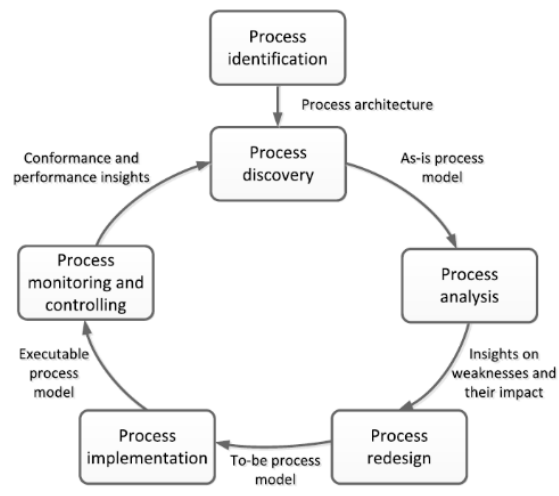

Gambar 2: Siklus hidup proses bisnis Sumber: (Dumas, M., M., \& Reijers, 2013)

\subsubsection{Process Identification}

Dalam fase ini, masalah bisnis diajukan, proses yang relevan dengan masalah yang dibahas diidentifikasi, dibatasi dan saling terkait. Hasil identifikasi proses adalah arsitektur proses baru atau yang diperbarui yang memberikan pandangan keseluruhan proses dalam organisasi dan hubungan mereka. Dalam beberapa kasus, identifikasi proses dilakukan secara paralel dengan untuk mengidentifikasi ukuran kinerja. Namun, dalam buku ini, kami akan mengaitkan identifikasi ukuran kinerja dengan fase analisis proses, mengingat bahwa ukuran kinerja sering digunakan untuk analisis proses (Vergidis, Tiwari, \& \& Majeed, 2007).

\subsubsection{Process Discovery}


Process Discovery atau penemuan proses adalah tahap pemodelan proses bisnis yang sedang berlangsung. Pada tahapan ini, keadaan saat ini dari masing-masing proses yang relevan didokumentasikan, biasanya dalam bentuk satu atau beberapa model proses (Vergidis, Tiwari, \& \& Majeed, 2007).

\subsubsection{Process Analyze}

Dalam fase ini, masalah yang terkait dengan proses apa adanya diidentifikasi, didokumentasikan dan kapan pun mungkin dikuantifikasi menggunakan ukuran kinerja. Hasil dari fase ini adalah kumpulan masalah terstruktur. Masalah-masalah ini biasanya diprioritaskan dalam hal dampaknya, dan kadangkadang juga dalam hal upaya yang diperkirakan diperlukan untuk menyelesaikannya (Vergidis, Tiwari, \& \& Majeed, 2007).

\subsubsection{Process Redesign}

Process Redesign atau perancangan ulang proses adalah tahapan perbaikan proses. Tujuan dari fase ini adalah untuk mengidentifikasi perubahan pada proses yang akan membantu untuk mengatasi masalah yang diidentifikasi pada fase sebelumnya dan memungkinkan organisasi untuk memenuhi tujuan kinerjanya. Untuk tujuan ini, beberapa opsi perubahan dianalisis dan dibandingkan dalam hal ukuran kinerja yang dipilih. Ini mensyaratkan bahwa proses desain ulang dan analisis proses berjalan seiring: Ketika opsi perubahan baru diusulkan, mereka dianalisis menggunakan teknik analisis proses. Akhirnya, opsi perubahan yang paling menjanjikan digabungkan, mengarah ke proses yang dirancang ulang. Hasil dari fase ini biasanya merupakan model proses yang akan datang, yang berfungsi sebagai dasar untuk fase berikutnya (Vergidis, Tiwari, \& \& Majeed, 2007).

\subsubsection{Process Implementation}

Dalam fase ini, perubahan yang diperlukan untuk berpindah dari proses yang saat ini diterapkan ke proses yang akan disiapkan disiapkan dan dilakukan. Implementasi proses mencakup dua aspek, yaitu manajemen perubahan organisasi dan otomatisasi proses. Manajemen perubahan organisasi mengacu pada serangkaian kegiatan yang diperlukan untuk mengubah cara kerja semua peserta yang terlibat dalam proses. Otomatisasi proses di sisi lain mengacu pada pengembangan sistem TI yang mendukung proses yang akan datang (Vergidis, Tiwari, \& \& Majeed, 2007).

\subsubsection{Process Monitoring and Controlling}

Proses pemantauan dan pengendalian. Setelah proses yang didesain ulang berjalan, data yang relevan dikumpulkan dan dianalisis untuk menentukan seberapa baik kinerja proses sehubungan dengan ukuran kinerja dan tujuan kinerja. Kesalahan berulang atau penyimpangan sehubungan dengan perilaku yang dimaksud diidentifikasi dan tindakan korektif dilakukan. Masalah-masalah baru kemudian dapat muncul, dalam proses yang sama atau dalam proses lainnya, yang membutuhkan siklus untuk diulang secara berkelanjutan (Vergidis, Tiwari, \& \& Majeed, 2007).

\subsection{Wawancara}

Tahapan wawancara dilakukan untuk menemukan dan mengidentifikasi proses bisnis yang ada di Dinas Perdagangan Kota XYZ, selain itu pada proses wawancara ini juga meliputi tahap Process Indentification dan Process Discovery. Proses wawancara dilakukan dengan menanyakan proses bisnis dan aktivitas yang ada berdasarkan tugas dan fungsi Dinas dan pemangku kepentingan, dan dilaksanakan kepada Sukaryanto selaku Sekertaris Dinas, Irawan selaku Kepala Bidang Perdagangan Dalam Negeri, Philipus Rimpa selaku Kepala Bidang Perdagangan Luar Negeri dan Baharudin selaku Kepala Bidang Sarana Perdagangan Dinas Perdagangan Kota XYZ. Hasil dari wawancara ini selanjutnya akan dilanjutkan kepada tahapan perancangan.

\subsection{Perancangan}

Tahapan perancangan dilakukan untuk menggambarkan proses bisnis yang telah diidentifikasi kedalam bentuk notasi dan menyempurnakan tahapan Process Discovery. Adapun bentuk notasi yang digunakan untuk merancang proses bisnis ini adalah dengan menggunakan Business Process 


\section{Analisis Proses Bisnis pada Dinas Perdagangan Kota XYZ dengan Menggunakan Business Process Management Lifecycle}

Modelling Notation. Proses bisnis Dinas Perdagangan Kota XYZ gambarkan dengan menggunakan aplikasi Bizagi Modeller versi 3.2.7.242.

\subsection{Evaluasi}

Tahapan evaluasi dilakukan untuk menilai dan menganalisis kekurangan dari proses bisnis yang saat ini sedang berlangsung (as is business process) di Dinas Perdagangan Kota XYZ. Evaluasi dilaksanakan untuk tahapan process Analyze. Pada tahapan ini akan dilakukan penilaian dan analisis kualitatif serta kuantitatif dari proses bisnis yang ada. Setelah proses penilaian, akan dirancangan proses bisnis perbaikan (to be business process).

\subsection{Kesimpulan}

Tahapan kesimpulan adalah untuk menemukan poin utama dari penelitian sebagai jawaban dari permasalahan yang ada. Kesimpulan diambil dari pada setiap tahapan yang telah dilakukan. Kesimpulan ini dapat berupa saran perbaikan dan hasil analisis serta evaluasi.

\section{Hasil dan Diskusi}

Hasil dan diskusi ini akan membahas mengenai analis proses bisnis yang ada pada Dinas Perdagangan Kota XYZ dengan menggunakan siklus hidup proses bisnis. Adapun hasil dan diskusi disajikan seperti berikut:

\subsection{Process Identification}

Adapun fungsi bisnis dari Dinas Perdagangan kota XYZ berdasarkan peraturan Walikota XYZ nomor 37 tahun 2016 adalah sebagai berikut: Perumusan kebijakan teknis di bidang perdagangan; Pelaksanaan pembinaan dan pengembangan di bidang perdagangan; Pengawasan dan pengendalian terhadap pelaksanaan kebijakan perdagangan; Pengaturan, perencanaan, penyelenggaraan, pengendalian teknis di bidangperdagangan; Pelaksanaan koordinasi, fasilitasi, sosialisasi, bimbingan teknis, supervisi penyelenggaraan urusan perdagangan; Pelaksanaan kerjasama, pemasaran dan promosi perdagangan; Pelaksanaan pembinaan, bimbingan dan pengendalian pemberian layanan perizinanurusan perdagangan; Pengoordinasian pemberdayaan urusan perdagangan; Pengelolaan UPT; Pelaksanaan monitoring, evaluasi, pengendalian dan pelaporan pertanggungjawaban pelaksanaan tugas; Pelaksanaan tugas lainnya yang diberikan oleh pimpinan/atasan sesuai dengan tugas dan fungsinya.

Berdasarkan fungsi bisnis pada Dinas Perdagangan kota XYZ diatas, maka diperoleh arsitekturkproses bisnis seperti gambar berikut:

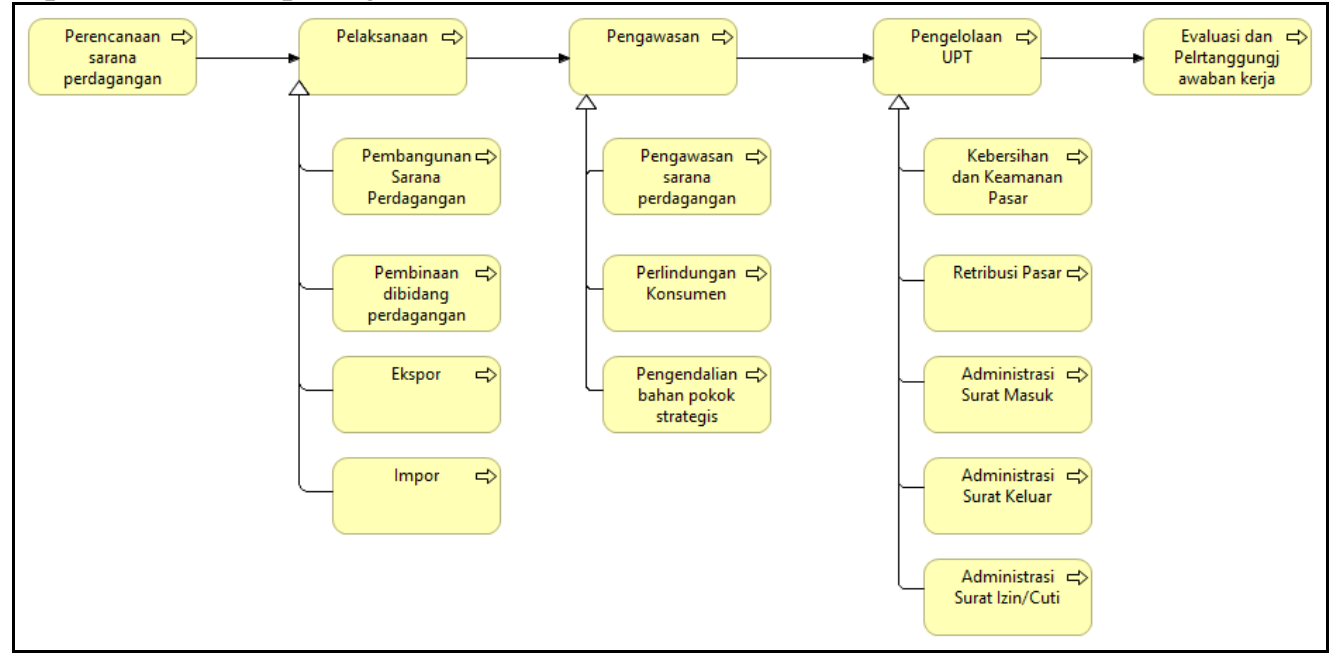

Gambar 3: Arsitektur proses pada Dinas Perdagangan Kota XYZ 


\subsection{Process Discovery}

Pada tahapan ini adalah memetakan seluruh proses bisnis yang ada pada Dinas Perdagangan Kota XYZ. Adapun hasil temuan proses bisnis tersebut adalah seperti berikut:

\subsubsection{Proses Bisnis Keseluruhan}

Proses bisnis keseluruhan diperoleh dengan melakukan wawancara terhadap para entitas bisnis di Dinas Perdagangan Kota XYZ. Adapun proses bisnis secara keseluruhan yang diperoleh setelah wawancara adalah seperti pada tabel berikut:

Tabel 2: Daftar proses bisnis saat ini pada Dinas Perdagangan Kota XYZ

\begin{tabular}{|c|c|c|}
\hline No & Index & Nama Proses Bisnis \\
\hline 1 & PB-AI-01.01 & Proses Umum \\
\hline 2 & PB-AI-02.01 & Perencanaan Sarana Perdagangan \\
\hline 3 & PB-AI-03.01 & Pelaksanaan \\
\hline 4 & PB-AI-04.01 & Pengawasan \\
\hline 5 & PB-AI-05.01 & Pengelolaan UPT \\
\hline 6 & PB-AI-06.01 & Evaluasi dan Pertanggungjawaban \\
\hline 7 & PB-AI-03.02 & Pembangunan Sarana Perdagangan \\
\hline 8 & PB-AI-03.03 & Pembinaan dibidang Perdagangan \\
\hline 9 & PB-AI-03.03.01 & Mengurus Surat Tugas \\
\hline 10 & PB-AI-03.03.02 & Melaksanakan Pembinaan \\
\hline 11 & PB-AI-03.02 & Ekspor \\
\hline 12 & PB-AI-03.02.01 & Membuat Janji Temu \\
\hline 13 & PB-AI-03.02.02 & Menegadakan Koordinasi \\
\hline 14 & PB-AI-03.02.03 & Mengadakan Kerjasama \\
\hline 15 & PB-AI-03.02.04 & Melakukan Pengiriman \\
\hline 16 & PB-AI-03.05. & Impor \\
\hline 17 & PB-AI-03.05.01 & Mengoordinasi \\
\hline 18 & PB-AI-03.05.02 & Menganalisis \\
\hline 19 & PB-AI-03.05.03 & Melakukan Kerjasama \\
\hline 20 & PB-AI-03.05.04 & Melakukan Pengiriman dan Evaluasi \\
\hline 21 & PB-AI-04.02 & Pengawasan Sarana Perdagangan \\
\hline 22 & PB-AI-04.02.01 & Melakukan Pengawasan Pasar \\
\hline 23 & PB-AI-04.02.02 & Mengevaluasi Pengawasan Pasar \\
\hline 24 & PB-AI-04.03 & Pengendalian Bahan Pokok Strategis \\
\hline 25 & PB-AI-04.03.01 & Menjalankan Operasi Pemeriksaan \\
\hline 26 & PB-AI-04.03.02 & Membuat Laporan Hasil Pemeriksaan \\
\hline 27 & PB-AI-04.04 & Perlindungan Konsumen \\
\hline 28 & PB-AI-04.04.01 & Menjalankan Monitoring \\
\hline 29 & PB-AI-04.04.02 & Membuat Laporan Hasil Kerja \\
\hline 30 & PB-AI-04.04.03 & Mengambil Keputusan \\
\hline 31 & PB-AI-04.04.04 & Melakukan Penertiban \\
\hline 32 & PB-AI-05.01 & Kebersihan dan Keamanan Pasar \\
\hline 33 & PB-AI-05.02 & Retribusi Pasar \\
\hline 34 & PB-AI-05.03 & Administrasi Surat Masuk \\
\hline 35 & PB-AI-05.04 & Administrasi Surat Izin/cuti \\
\hline 36 & PB-AI-05.05 & Administrasi Surat Keluar \\
\hline
\end{tabular}

\subsubsection{Proses Bisnis Ekspor}

Proses bisnis Ekspor pada Dinas Perdagangan Kota XYZ terdiri dari beberapa sub proses. Sub proses itu adalah membuat janji temu, kemudian dilanjutkan dengan mengadakan koordinasi, dilanjutkan 


\section{Analisis Proses Bisnis pada Dinas Perdagangan Kota XYZ dengan Menggunakan Business Process Management Lifecycle}

dengan proses mengadakan kerjasama, dan kemudian melakukan pengiriman. Pada sub proses mengadakan kerjasama, bisa terjadi permasalahan berupa salah satu pihak menolak untuk bekerja sama, hal ini akan mengakibatkan sub proses melakukan pengiriman tidak dapat dijalankan. Adapun gambaran dari proses bisnis tersebut adalah seperti berikut:

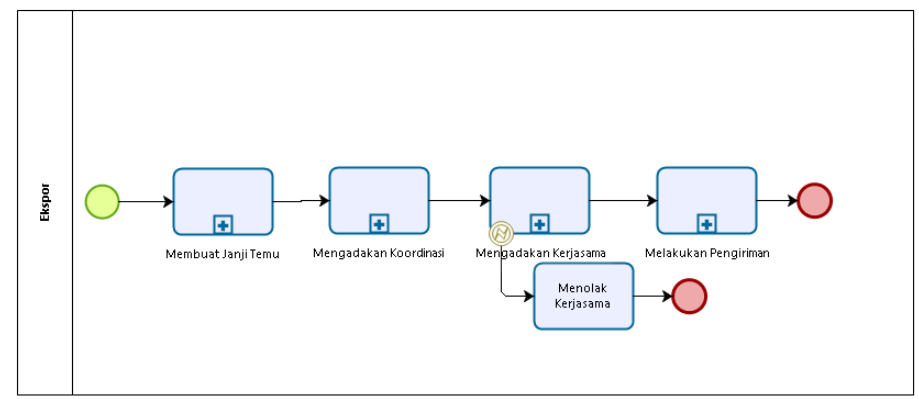

Gambar 4: Proses Ekspor yang saat ini di Dinas Perdagangan Kota XYZ

\subsubsection{Proses Bisnis Impor}

Proses bisnis Impor pada Dinas Perdagangan Kota XYZ terdiri dari beberapa sub proses. Sub proses itu adalah mengoordinasi, kemudian dilanjutkan dengan menganalisis, dilanjutkan dengan proses mengadakan kerjasama, dan kemudian melakukan pengiriman dan evaluasi. Pada sub proses mengadakan kerjasama, bisa terjadi permasalahan berupa salah satu pihak menolak untuk bekerja sama, hal ini akan mengakibatkan sub proses melakukan pengiriman dan evaluasi tidak dapat dijalankan. Adapun gambaran dari proses bisnis tersebut adalah seperti berikut:

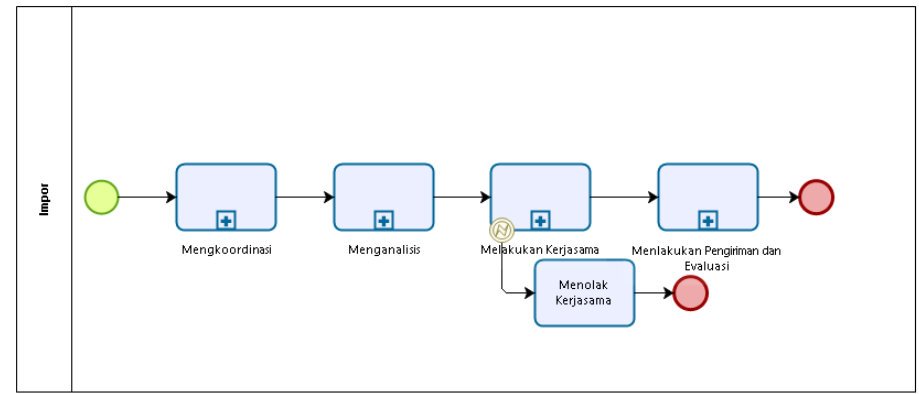

Gambar 5: Proses bisnis Impor saat ini di Dinas Perdagangan Kota XYZ

\subsubsection{Proses Bisnis Melakukan Pengiriman dan Evaluasi}

Proses bisnis Melakukan Pengiriman dan Evalusi adalah isi dari sub proses yang terdapat pada proses bisnsi Impor. Proses bisnis ini dimulai oleh Dinas Pedagangan Luar kota yang memberikan kabar bahwa akan mengadakan pengiriman, pemberitahuan ini dikabarkan kepada Kepala Bidang Luar Negeri Dinas Pedagangan Kota XYZ (Kabid Luar Negeri), selanjutnya para pengusaha atau pelau ekspor akan melaksanakan transaksi pengiriman. Kemudian dari Dinas Luar Kita akan membuat laporan pengiriman yang ditujukan kepada Kabid Luar Negeri. Kabid Luar Negeri akan berkoordinasi dengan Kabid Dalam Negeri untuk mendiskusikan terkait bahan pokok pada Dinas Perdagangan Kota XYZ apabila kontrak kerja sama akan segera berakhir, jika kerja sama masih dilanjutkan, maka proses akan diulang mulai pengiriman dari Dinas Luar Kota, akan tetapi apabil tidak akan dilanjutkan, maka kerja sama akan berakir. Adapun gambaran proses bisnis tersebut adalah seperti berikut: 
Analisis Proses Bisnis pada Dinas Perdagangan Kota XYZ dengan Menggunakan Business Process Management Lifecycle

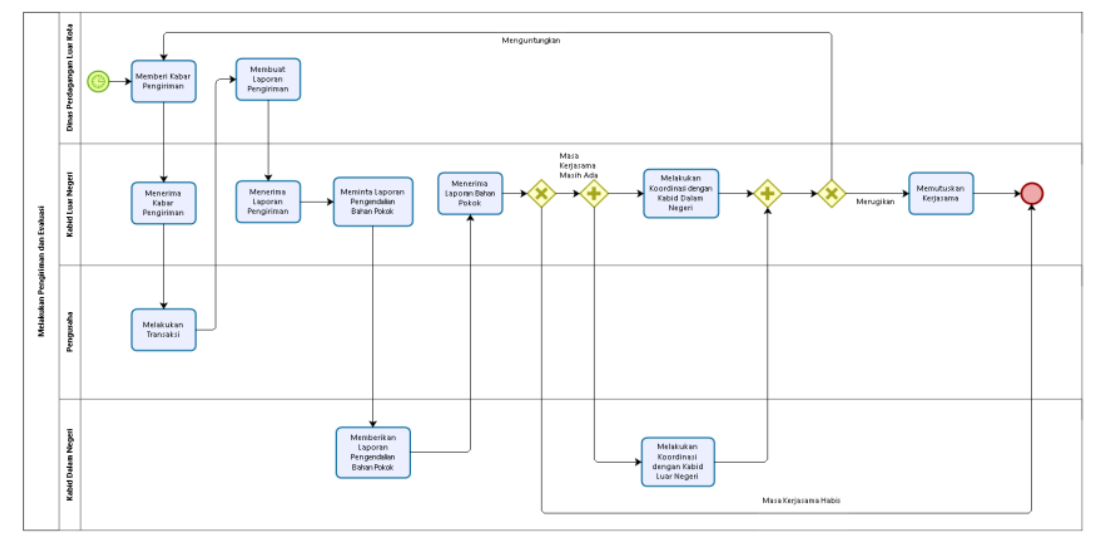

Gambar 6: Proses bisnis Melakukan Pengiriman dan Evaluasi saat ini di Dinas Perdagangan Kota $\mathrm{XYZ}$

\subsection{Process Analyze}

Adapun pada tahapan analisis proses meliputi tahapan analisis kualitatif serta analisis kelemahan dan redesain. Tahapan tersebut adalah seperti berikut:

\subsubsection{Analisis Kualitatif}

Analisis kualitatif dilakukan dengan menganalisis aktivitas setiap proses bisnis yang ada. Aktivitas bisa bersifat Value Added (VA), Business Value Added (BVA), Non Value Added (NVA). Hasilnya akan dapat berupa saran agar aktivitas yang bersifat NVA agar dihapuskan dari proses. Adapun temuan NVA pada proses bisnis di Dinas Perdagangan Kota XYZ adalah seperti berikut:

Tabel 3: Tabel hasil analisis kualitatif

\begin{tabular}{|c|c|c|c|c|}
\hline Indeks & Nama Proses & Aktivitas & Entitas & Klasifikasi \\
\hline \multirow{15}{*}{$\begin{array}{l}\text { PB-AI- } \\
\text { 03.05.04 }\end{array}$} & \multirow{15}{*}{$\begin{array}{l}\text { Melakukan } \\
\text { Pengiriman } \\
\text { dan Evaluasi }\end{array}$} & Memberi Kabar pengiriman & $\begin{array}{l}\text { Dinas Perdagangan } \\
\text { Luar Kota }\end{array}$ & NVA \\
\hline & & $\begin{array}{l}\text { Membuat laporan } \\
\text { pengiriman }\end{array}$ & $\begin{array}{l}\text { Dinas Perdagangan } \\
\text { Luar Kota }\end{array}$ & BVA \\
\hline & & $\begin{array}{l}\text { Menerima kabar } \\
\text { pengiriman }\end{array}$ & Kabid Luar Negeri & BVA \\
\hline & & $\begin{array}{l}\text { Menerima laporan } \\
\text { pengiriman }\end{array}$ & Kabid Luar Negeri & BVA \\
\hline & & $\begin{array}{l}\text { Menerima laporan bahan } \\
\text { pokok strategis }\end{array}$ & Kabid Luar Negeri & BVA \\
\hline & & $\begin{array}{l}\text { Melakukan Koordinasi } \\
\text { dengan Kabid Dalam } \\
\text { Negeri }\end{array}$ & Kabid Luar Negeri & BVA \\
\hline & & Memutuskan Kerjasama & Kabid Luar Negeri & VA \\
\hline & & Melakukan Transaksi & Pengusaha & VA \\
\hline & & $\begin{array}{l}\text { Memberikan Laporan } \\
\text { pengendalian bahan pokok }\end{array}$ & Kabid Dalam Negeri & BVA \\
\hline & & $\begin{array}{l}\text { Melakukan koordinasi } \\
\text { dengan kabid luar negeri }\end{array}$ & Kabid Dalam Negeri & BVA \\
\hline & & Menerima Konsep Surat & Kasubag TU & BVA \\
\hline & & Memaraf Surat & Kepala TU & BVA \\
\hline & & $\begin{array}{l}\text { Menerima dan mengarsip } \\
\text { surat }\end{array}$ & Administrasi & BVA \\
\hline & & Menerima Surat & Kepala UPT & BVA \\
\hline & & $\begin{array}{l}\text { Menerima dan } \\
\text { menandatangani }\end{array}$ & Kepala UPT & VA \\
\hline
\end{tabular}




\subsubsection{Analisis Kelemahan dan Redesain}

Analiasis kelemahan di dapatkan berdasarkan hasil analisis kualitatif dan dengan membandingkan proses bisnis saat ini di Dinas Perdagangan Kota XYZ dengan tugas dan fungsi bisnis Kementerian Perdagangan Republik Indonesia yang sesuai dengan Peraturan Presiden Republik Indonesia Nomor 48 Tahun 2015 Tentang Kementerian Perdagangan. Adapun hasil temuan dari analisis kelemahan dan redesain dari proses bisnis adalah seperti berikut:

Tabel 4: Hasil analisis kelemahan dan redesain proses bisnis saat ini

\begin{tabular}{|c|c|c|c|c|c|c|}
\hline No & Indeks & Proses Bisnis & Proses as-is & Weakness & Proses to-be & $\begin{array}{l}\text { Deskripsi } \\
\text { Perubahan }\end{array}$ \\
\hline 1 & $\begin{array}{c}\text { PB-AI- } \\
03.02\end{array}$ & Ekspor & - & $\begin{array}{l}\text { Apabila } \\
\text { dibandingkan } \\
\text { dengan } \\
\text { peraturan } \\
\text { Peraturan } \\
\text { Presiden } \\
\text { Republik } \\
\text { Indonesia } \\
\text { Nomor } 48 \text { Tahun } \\
2015 \text { Tentang } \\
\text { Kementerian } \\
\text { Perdagangan, } \\
\text { maka dinas } \\
\text { perdagangan } \\
\text { tidak tidak } \\
\text { memiliki proses } \\
\text { pengawasan } \\
\text { pada saat proses } \\
\text { pengiriman yang } \\
\text { termasuk } \\
\text { transaksi antara } \\
\text { pengusaha, } \\
\text { menyebabkan } \\
\text { kurangnya } \\
\text { pengendalian } \\
\text { permasalahan }\end{array}$ & $\begin{array}{l}\text { Melakukan } \\
\text { Pengawasan } \\
\text { Pengiriman }\end{array}$ & $\begin{array}{l}\text { Proses Bisnis } \\
\text { ditambahkan } \\
\text { sub proses } \\
\text { Melakukan } \\
\text { Pengawasan } \\
\text { Pengiriman, } \\
\text { hal ini } \\
\text { merujuk } \\
\text { kepada fungsi } \\
\text { entitas } \\
\text { Kementrian } \\
\text { Perdagangan } \\
\text { bahwa adanya } \\
\text { pelaksanaan } \\
\text { pengawasan } \\
\text { kegiatan } \\
\text { perdagangan } \\
\text { yang termasuk } \\
\text { kegiatan } \\
\text { Ekspor }\end{array}$ \\
\hline 2 & $\begin{array}{l}\text { PB-AI- } \\
03.05 .\end{array}$ & Impor & - & $\begin{array}{l}\text { Apabila } \\
\text { dibandingkan } \\
\text { dengan } \\
\text { peraturan } \\
\text { Kementerian } \\
\text { Perdagangan } \\
\text { Peraturan } \\
\text { Presiden } \\
\text { Republik } \\
\text { Indonesia } \\
\text { Nomor 48 Tahun } \\
\text { 2015 Tentang } \\
\text { Kementerian } \\
\text { Perdagangan, } \\
\text { maka dinas } \\
\text { perdagangan } \\
\text { tidak tidak } \\
\text { memiliki proses } \\
\text { pengawasan }\end{array}$ & $\begin{array}{l}\text { Melakukan } \\
\text { Pengawasan } \\
\text { Pengiriman }\end{array}$ & $\begin{array}{l}\text { Proses Bisnis } \\
\text { ditambahkan } \\
\text { sub proses } \\
\text { Melakukan } \\
\text { Pengawasan } \\
\text { Pengiriman, } \\
\text { hal ini } \\
\text { merujuk } \\
\text { kepada fungsi } \\
\text { entitas } \\
\text { Kementrian } \\
\text { Perdagangan } \\
\text { bahwa adanya } \\
\text { pelaksanaan } \\
\text { pengawasan } \\
\text { kegiatan } \\
\text { perdagangan } \\
\text { yang termasuk } \\
\text { kegiatan Impor }\end{array}$ \\
\hline
\end{tabular}



Process Management Lifecycle

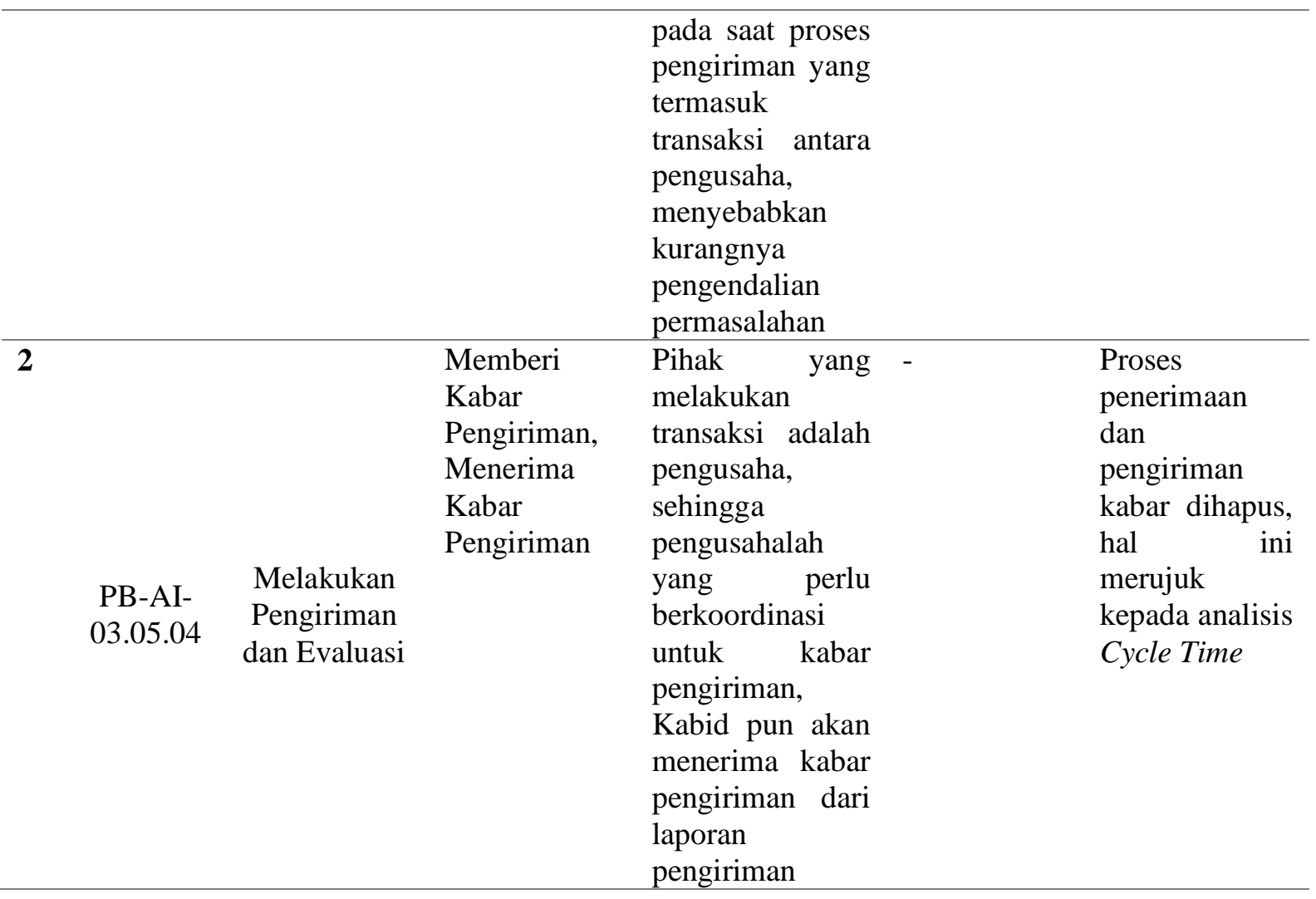

\subsection{Quality of Business Process}

Quality of Business Process atau kualitas dari proses bisnis adalah pengukuran terhadap proses bisnis yang saat ini sedang berlangsung di Dinas Perdagangan Kota XYZ. Hal yang diukur dari proses bisnis adalah jumlah noda, jumlah aktivitas, jumlah panah, jumlah gerbang (gateway), diameter (panjang proses), rata-rata tingkat konektor, dan tingkat kedalaman dari proses bisnis. Adapun hasil untuk kualitas proses bisnis adalah seperti berikut:

Tabel 5: Hasil kualitas proses bisnis pada Dinas Perdagangan Kota XYZ

\begin{tabular}{|c|c|c|c|c|c|c|c|c|c|}
\hline No & Index & $\begin{array}{c}\text { Nama Proses } \\
\text { Bisnis }\end{array}$ & 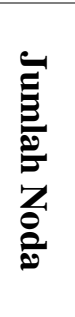 & 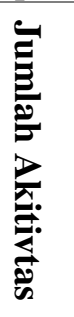 & 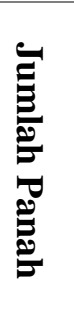 & 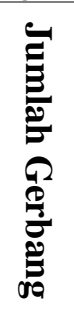 & 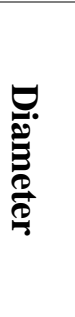 & 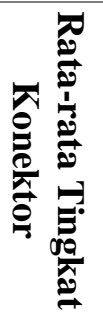 & 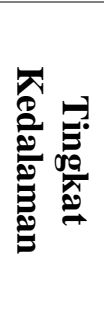 \\
\hline 1 & PB-AI-03.02 & Ekspor & 8 & 5 & 7 & 0 & 6 & 0 & 0 \\
\hline 2 & PB-AI-03.05. & Impor & 8 & 5 & 7 & 0 & 6 & 0 & 0 \\
\hline 3 & PB-AI-03.05.04 & $\begin{array}{l}\text { Melakukan } \\
\text { Pengiriman dan } \\
\text { Evaluasi }\end{array}$ & 17 & 11 & 19 & 4 & 16 & 3 & 1 \\
\hline
\end{tabular}

\subsection{Process Redesign}

Redesain proses bisnis ini berisikan tentang perbaikan proses bisnis berdasarkan hasil analisis diatas. Adapun perbaikan untuk proses bisnis di Dinas Perdagangan Kota XYZ adalah seperti berikut:

\subsubsection{Rancangan Perbaikan Proses Bisnis Ekspor}


Perbaikan pada proses bisnis Ekspor di Dinas Perdagangan Kota XYZ adalah dengan menambahkan proses Melakukan Pengawasan Pengiriman. Proses Melakukan Pengawasan Pengiriman dijalankan bersamaan dengan peroses Pengiriman. Adapun rancangan perbaikan proses bisnis Ekspor yang dilambangkan dengan BPMN adalah seperi pada gambar berikut ini:

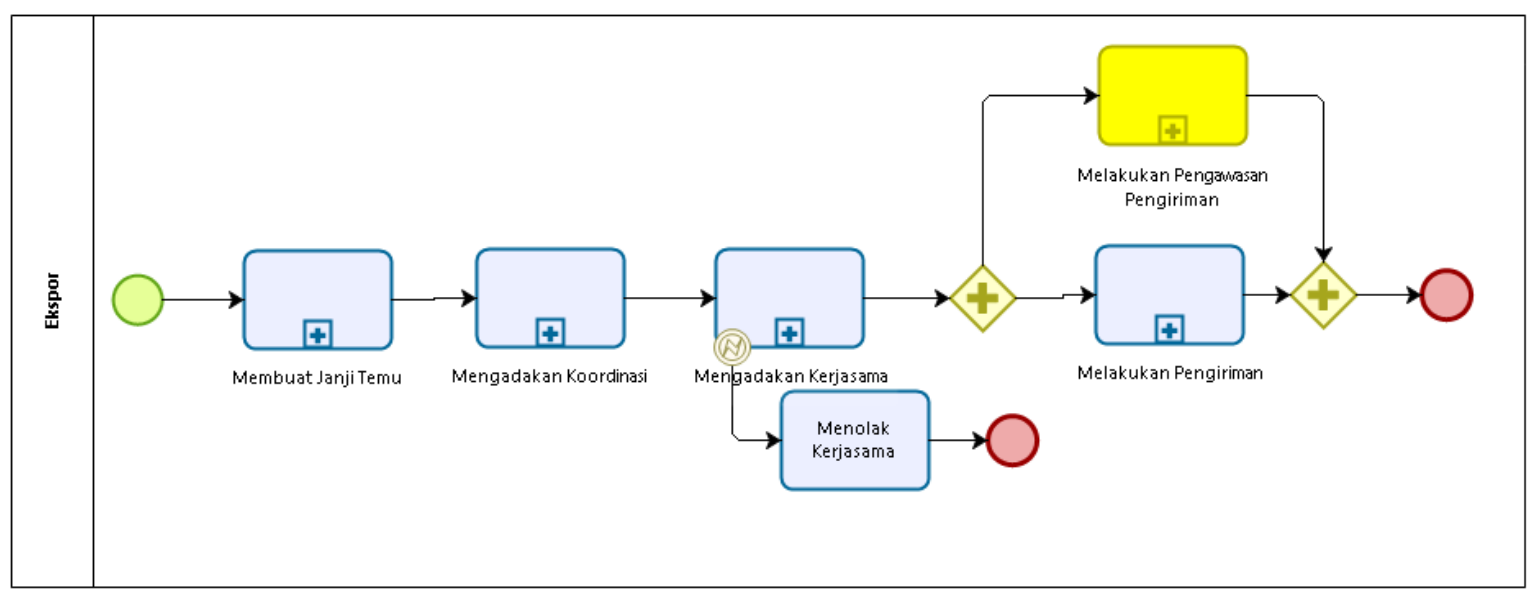

Gambar 7: Redesain proses bisnis Ekspor pada Dinas Perdagangan Kota XYZ

\subsubsection{Rancangan Perbaikan Proses Bisnis Impor}

Perbaikan pada proses bisnsi Impor di Dinas Perdagangan Kota XYZ adalah dengan menambahkan proses Melakukan Pengawasan Pengiriman. Proses Melakukan Pengawasan Pengiriman dijalankan bersamaan dengan peroses Pengiriman. Adapun rancangan perbaikan proses bisnis Impor yang dilambangkan dengan BPMN adalah seperi pada gambar berikut ini:

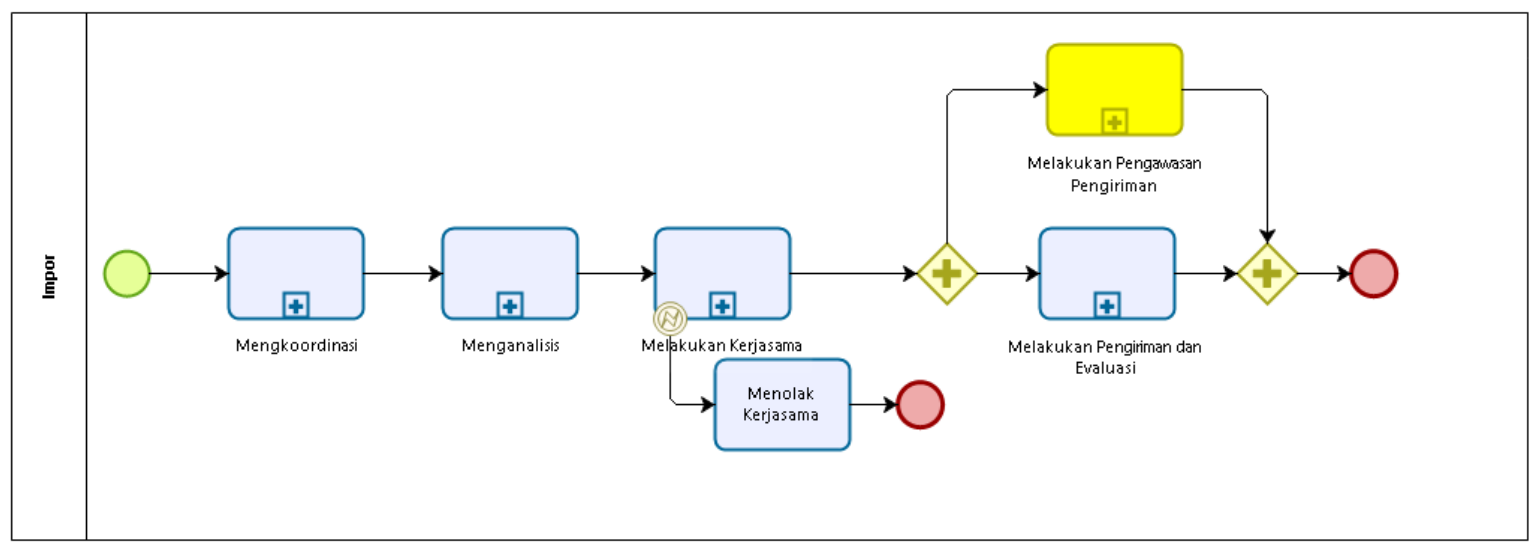

Gambar 8: Redesain proses bisnis Impor pada Dinas Perdagangan Kota XYZ

\subsubsection{Rancangan Perbaikan Proses Bisnis Melakukan Pengiriman dan Evaluasi}

Perbaikan pada proses bisnis Melakukan Pengiriman dan Evaluasi adalah dengan menghapus aktivitas yang terklasifikasi Non Value Added (NVA) yakni aktivitas Memberi Kabar Pengiriman, proses ini dihapus berdasarkan hasil analisis kelemahan dan redesain pada tabel 4. Adapun rancangan perbaikan proses bisnis Melakukan Pengiriman dan Evaluasi adalah seperti pada gambar berikut: 


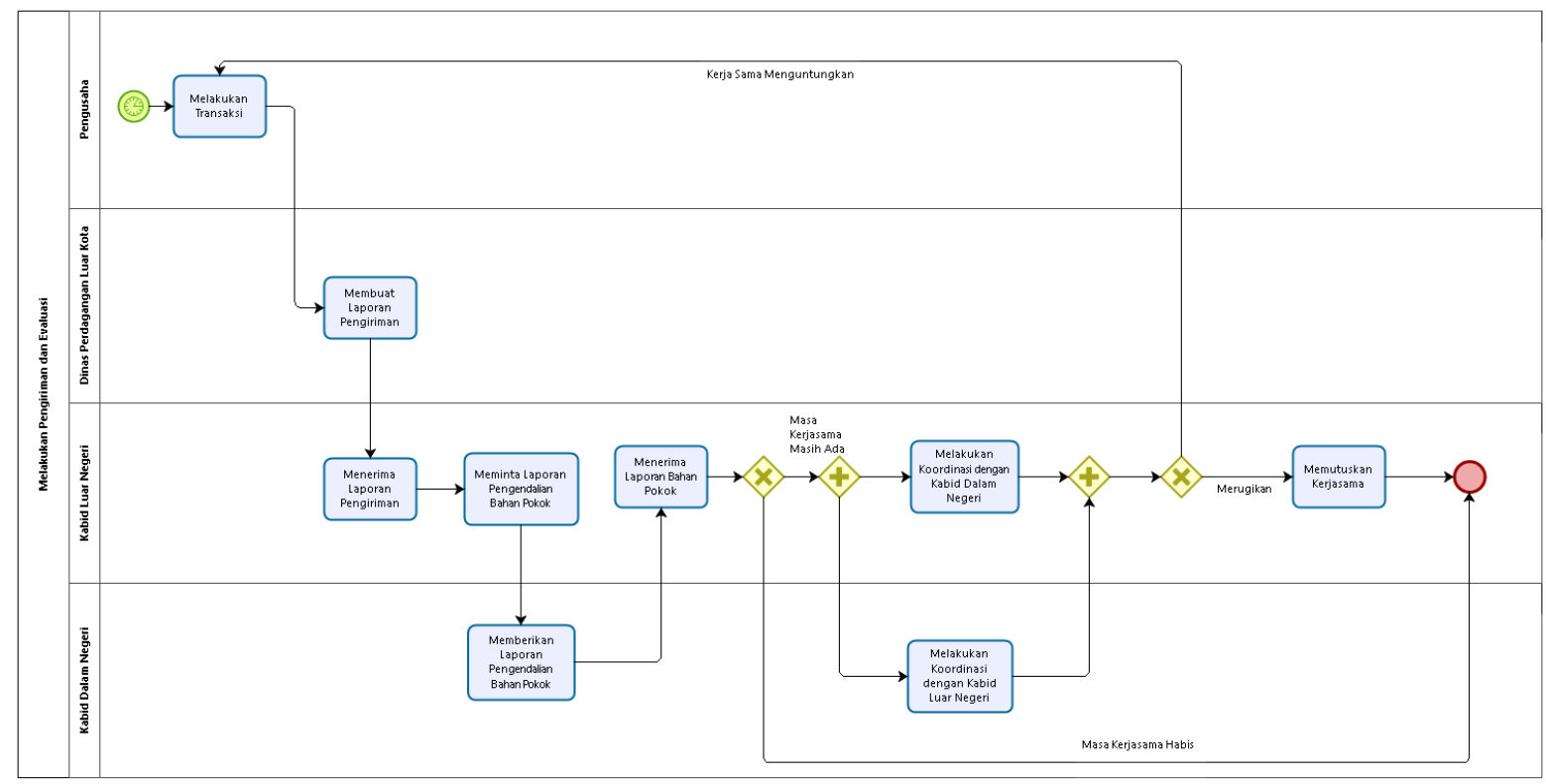

Gambar 9: Redesain proses bisnis Melakukan Pengiriman dan Evaluasi pada Perdagangan Kota XYZ

\section{Kesimpulan}

Adapun kesimpulan yang dapat diperoleh dari pelaksanaan penelitian proses bisnis pada Dinas Perdagangan Kota XYZ adalah terdapat 3 rancangan perbaikan terhadap proses bisnis yang berlaku saat ini, yakni pada proses Impor, Ekspor, dan Melakukan Pengiriman dan Evaluasi. Adapun perbaikan yang dilakukan pada proses bisnis Ekspor adalah dengan menambahkan sub proses Melakukan pengawasan yang dilakukan bersamaan dengan sub proses Melakukan Pengiriman. Perbaikan yang dilakukan pada proses bisnis Impor adalah dengan menambahkan sub proses Melakukan Pengawasan yang dilakukan bersamaan dnegan sub proses Melakukan Pengiriman. Perbaikan yang dilakukan pada proses Melakukan Pengiriman dan Evaluasi adalah dengan menghapuskan aktivitas yang terklasifikasi sebagai Non Value Added (NVA), yakni aktivitas Memberi Kabar Pengiriman.

\section{Ucapan Terima Kasih}

Penulis ucapkan terima kasih kepada orang tua atas dukungan, dan rekan-rekan dari Program Studi Sistem Informasi Institut Teknologi Kalimantan, selain itu penulis ucapkan terima kasih pula kepada Dinas Perdagangan Kota XYZ yang telah memberikan penulis kesempatan untuk dapat melakukan penelitian terhadap proses bisnis yang ada sehingga penelitian ini dapat diselesaikan. Selain itu, penulis ucapkan pula terima kasih kepada seluruh pihak yang telah membantu dalam pembuatan penelitian serta penulisan jurnal ilmiah ini.

\section{Referensi}

Dumas, M., L. R., M., M. J., \& Reijers, H. A. (2013). Fundamentals of business process management (Vol. 1, p. 2). Heidelberg: Springer.

Ramdhani, M. A. (2015). Pemodelan Proses Bisnis Sistem Akademik Menggunakan Pendekatan Business Process Modelling Notation (BPMN)(Studi Kasus Institusi Perguruan Tinggi XYZ). Jurnal Informasi, 83-93.

Rumapea, S. A. (2010). Analisis proses bisnis pada distributor XYZ menggunakan tools pemodelan IDEF0. In Seminar Nasional Aplikasi Teknologi Informasi (SNATI). 
Analisis Proses Bisnis pada Dinas Perdagangan Kota XYZ dengan Menggunakan Business Process Management Lifecycle

Van Der Aalst, W. M., Ter Hofstede, A. H., \& Weske, M. (2003, June). Business process management: A survey. In International conference on business process management (pp. 1-12). Springer, Berlin, Heidelberg.

Vergidis, K., Tiwari, A., \& \& Majeed, B. (2007). Business process analysis and optimization: Beyond reengineering. IEEE Transactions on Systems, Man, and Cybernetics, Part C (Applications and Reviews), 69-82. 